\title{
Numerical Simulation of Fire Resistance Test for Gas Turbine Component Using Coupled CFD/FEM Approach
}

\author{
K. Y. Mokhov ${ }^{1},{ }^{1}$ A. Y. Kudryavtsev, ${ }^{1}$ O. V. Voronkov, ${ }^{1}$ E. B. Voronina, ${ }^{1}$ S. V. Sukhov, ${ }^{1}$ \\ A. A. Ryabov, ${ }^{1}$ Y. N. Zhurenkov, ${ }^{2}$ A. V. Soloveva, ${ }^{2}$ and A. V. Grigoriev ${ }^{2}$ \\ ${ }^{1}$ Sarov Engineering Center, Technopark «Sarov», Region, Nizhny Novgorod, Russia \\ ${ }^{2}$ JSC «UEC-Klimov», St. Petersburg, Russia \\ Correspondence should be addressed to K. Y. Mokhov; kmokhov@saec.ru
}

Received 28 May 2020; Revised 5 September 2020; Accepted 5 October 2020; Published 29 October 2020

Academic Editor: Antonio Andreini

Copyright ( $) 2020 \mathrm{~K}$. Y. Mokhov et al. This is an open access article distributed under the Creative Commons Attribution License, which permits unrestricted use, distribution, and reproduction in any medium, provided the original work is properly cited.

\begin{abstract}
The article presents the implementation of CFD/FEM approach for real oil tank of the gas turbine engine for the purposes of prediction of the component behavior under the local impact of a burner jet. The model takes into account heat and mass transfer problems as well as strength problems that are solved using a one way coupled fluid-structure interaction method. Results of the blind test simulation are compared and show good agreement with available experimental data.
\end{abstract}

\section{Introduction}

One of the key requirements for gas-turbine engines (GTE) is their operation safety in various modes, including emergency situations, such as fires. Fire safety of GTE is regulated by the Federal Aviation Regulation Part 33.17 [1], according to which all components of GTEs containing flammable liquids must meet at least fire resistance requirements.

The traditional approach to prove component fire resistance is a full-scale test, in which the component is placed into a burner flame with the flame temperature of $T=1100$ $\pm 80^{\circ} \mathrm{C}[2]$. The burner is directed to expert-defined elements of the component, or a series of tests is carried out where the burner is directed to various elements of the component to identify the weakest one. The component is considered to be fire resistant if it is capable of withstanding the application of heat for 5 minutes. The experimental approach shows all possible mechanisms of destruction of the component (melting, thermal decomposition, combustion, etc.). However, this approach provides limited information on the test object behavior and requires significant costs for manufacturing a material part and conducting experiments. In case of failure of the test, it does not always provide enough information to define ways to refine the design of the component.
Another drawback, the results of the tests are obtained at the last stage when the component is already manufactured.

The necessity to predict the behavior of the component under fire stress is confirmed by the breadth of scientific research on this topic [3-11]. The most promising and accurate approach is based on coupled CFD-FEM analysis of the component behavior under fire-resistance tests. Detailed description of this approach can be found in the research of Prieler et al. [3, 4] and Malendowski [5].

Computational approach provide opportunity to analyze component behavior under fire conditions at early design stages and optimally eliminate identified design flaws, thereby reducing the development time and cost, as well as improving the product quality. The model presented in this article involves a coupled computer simulation of external air flow, thermal state, and stresses in the component under the influence of the flame jet.

Unlike other research [3-7, 9-11] where all tests are performed on simplified models/coupons, this study analyses highly detailed complex geometry multimaterial assembly of the real component used in operational gas turbine engine. Moreover, it is typical for academia that experiment and computational analysis is performed by the same group of people working on the same project, which provide 
opportunity to tune the model to experimental results. In this work, experiment and simulation has been performed absolutely independently, by different legal entities. Experiment has been performed by certification authority empowered to provide conclusion for component power safety in Russia. Computational analysis has been performed as a blind test with comparison of the results only after finalization of the work reports. The only common inputs for experiment and computational approach was fire safety test procedure ISO 2685 [2] and expert-defined locations of burner impact. Simulation team used CAD geometry of oil tank. Certification authority was testing real oil tank produced based on shared CAD geometry.

\section{Problem Statement and Solution Methods}

The article considers the problem of flame jet impact for the duration of $t=5$ minutes on a steel oil tank partially filled with oil circulating with a given flow rate. The burner parameters according to ISO 2685 [2] are the following:

(i) Burner flame diameter is no less than $D=100 \mathrm{~mm}$

(ii) Flame temperature at the target is $T=(1100 \pm 80)^{\circ} \mathrm{C}$

(iii) Heat flux density at the target is $q=(116 \pm 10)$ $\mathrm{kW} / \mathrm{m}^{2}$

Figure 1 shows the zones of the burner heat impact on the oil tank elements. The first zone is borosilicate gauge glass, the second zone is the area of an oil return pipe, and the third zone is the area of a drain valve. Sealing elements correspond to OST 1 14645-89 [12] and have upper operational temperature limit of $300^{\circ} \mathrm{C}$.

Flame jet diffusion and thermal distribution is calculated using the finite volume spatial discretization coupled with the implicit time integration scheme implemented in STAR$\mathrm{CCM}+[13]$. The solution of the linearized problem at the integration step is carried out by the iterative multigrid AMG solver with the preconditioner. The iteration convergence is controlled by monitoring residuals for a system of linear algebraic equations and values of the main gasdynamic values at representative points. Since the hot gases outflow from the burner is turbulent, RANS k- $\omega$ SST turbulence model is used in the calculation [14].

Structural stresses caused by thermal gradients are defined by the finite element method in the Abaqus software package [15]. The material state equations are stated on the basis of the flow theory with translationally isotropic hardening [16], taking into account the dependences of material mechanical properties on temperatures. The linearized equation system is solved using the implicit method; the nonlinearity is resolved by Newton iterative gradient method [17].

Two discrete models replicating the structure of the real component and fire test environment were developed for the numerical solution of the problem:

(i) Finite volume model (FVM), with 44 million cells, to solve the problem of conjugate heat transfer, developed on the basis of trimmed hexagonal cells. 16

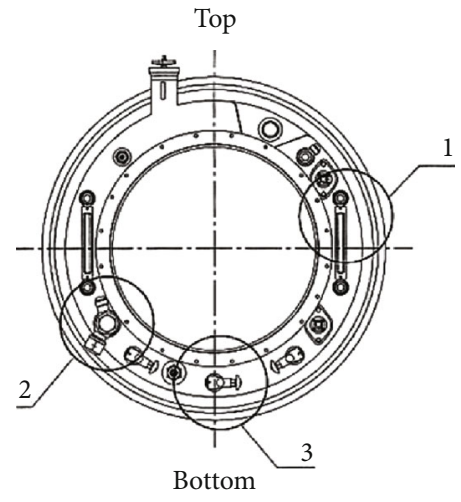

Figure 1: Zones affected by the burner flame heat.

layers of prismatic cells are formed on the oil tank walls with the first layer thickness of $h=0.01 \mathrm{~mm}$, which provides the value of the nondimensional parameter $\mathrm{Y}^{+} \sim 1$

(ii) Finite element model (FEM), with 1.5 million cells, with a typical spatial resolution of $1 \times 1 \times 1.5 \mathrm{~mm}$ to determine the stress-strain state of the structure, is developed on the basis of 20-node finite elements with second order spatial approximation with the reduced volume integration

Fragments of the developed discrete models are shown in Figures 2 and 3.

\section{Experimental and Numerical Results}

During the experiments, the main goal was to confirm that oil tank complies to fireproof requirements, which differs from the fire resistant by extending the time requirement to withstand the application of heat from 5 minutes to 15 minutes [2]. The results obtained in the experiments with the directional flame impact on various areas are as follows:

(i) in the gauge glass area, melting was recorded at $t_{1 \exp }=286 \mathrm{~s}$ after application of the heat of the burner

(ii) in the area of the oil return pipe, depressurization of the sealing elements occurred at $t_{2 \exp }=282 \mathrm{~s}$

(iii) in the area of the drain valve, no failures were identified

The conclusion of the failure of the case during the experiment has been done visually based on camera recording of the tests and thorough inspection of the oil tank after the end of the test.

The most critical part of the computational model is to obtain adequate boundary conditions.

At the first calculation stage, the computer burner model is tuned following ISO 2685 procedure [2] for burner calibration with the following steps. 


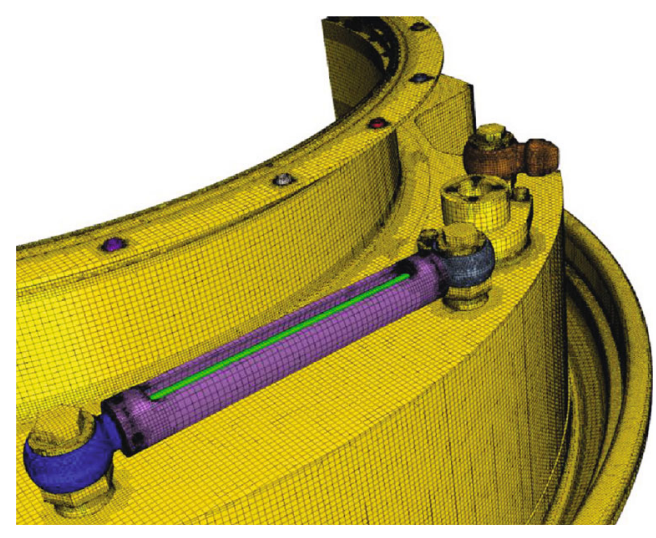

FIgURE 2: Finite volume model.

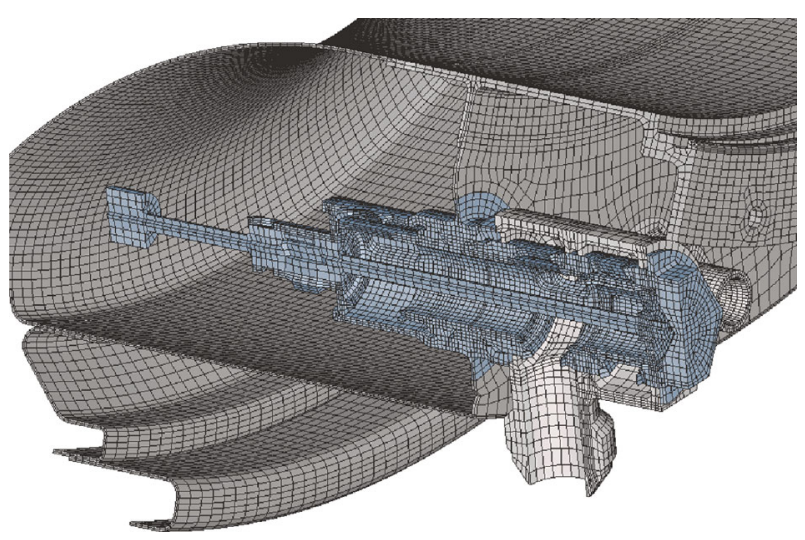

Figure 3: Oil tank finite element model.

Step 1: the flame temperature is estimated at a given distance from the burner.

Step 2: the flame heat flow in the target area is estimated by calculating the heating of the water in the copper tube with an outer diameter of dpipe $=12 \mathrm{~mm}$, under the influence of the burner flame.

This calculation stage results in finding boundary conditions that allow recreating burner integral parameters used in the experiment. The validity of such approach has been also demonstrated by our previous research [18].

The grid convergence in the numerical solution of the heat and mass transfer problem is proved by comparing results of the stationary calculations on two finite volume models with dimensions of 44 million and 76 million cells. The numerical experiments show that differences in the solutions do not exceed 3\%; therefore, all calculation studies are carried out with finite volume model with 44 million cells.

The size and number of elements for FEM has been selected based on Abaqus User Guide [15], stipulating the need of use of at least 2 second order spatial approximation elements with the reduced volume integration for the thickness of the material to capture "smooth" strain gradients. The size of the element was also examined based on the stress-strain state of the component to ensure no underresolved gradients of stress intensity.

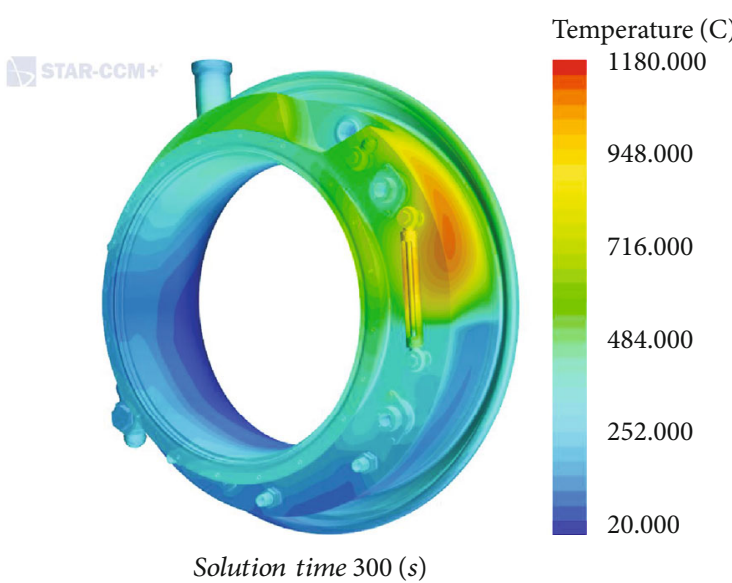

FIGURE 4: Temperature of the oil tank elements for gauge glass fire zone at $t=5$ minutes.

The numerical results for specified in Figure 1 flame impact zones provide a large amount of information on parameters of the gas jet, distribution of pressure, temperature, and the stress-strain state of the oil tank and its separate elements, as well as their changes over time.

3.1. Gauge Glass Fire Zone. Figure 4 shows the temperature distribution on the oil tank surface at $t=5 \mathrm{~min}$. Maximum temperature is realized at oil tank steel case and gauge glass. Figure 5 shows the value of maximum temperature of these components during the test. The temperature of the case reaches $T_{\text {steel }}^{\max }=1100^{\circ} \mathrm{C}$, yet since the melting temperature of the steel is $T_{\text {steel }}^{\text {melting }}=1496^{\circ} \mathrm{C}$ thermal impact by itself does not lead to disruption of the element. Minimum temperature of the case does not exceed $T_{\text {steel }}^{\min }=120^{\circ} \mathrm{C}$. The high temperature gradient in the body causes plastic deformations up to $\varepsilon_{\text {max }} \sim 7,5 \%$, yet the body containment is maintained. For all reviewed cased deformation of the steel case does not lead to disruption of the oil tank, thus relative figures are not shown in this article.

Temperature of the gauge glass in the simulation exceeds its melting point at $t_{1}^{\text {num }}=220 \mathrm{~s}$. It means that there is a high risk the gauge glass cannot withstand the fire resistant classification.

Obtained time in the simulation is close to the through melting point recorded in the experiment: $t_{1}^{\exp }=286 \mathrm{~s}$.

Figure 6 shows the area of the gauge glass exceeding the melting point. Bottom of the gauge glass has much lower temperature since it is filled with oil that effectively consumes the heat.

3.2. Oil Return Pipe Fire Zone. Figure 7 shows the temperature distribution on the oil tank surface at $t=5 \mathrm{~min}$. The temperature of the oil tank is much lower than in previous case, since the flame is directed to the zone washed by oil. Figure 8 shows the value of maximum temperature of the components during the test. The sealing elements are the most difficult to analyze due to the lack of information about degradation of material properties at high temperatures. Therefore, it is not possible to make a firm conclusion on withstanding fire 


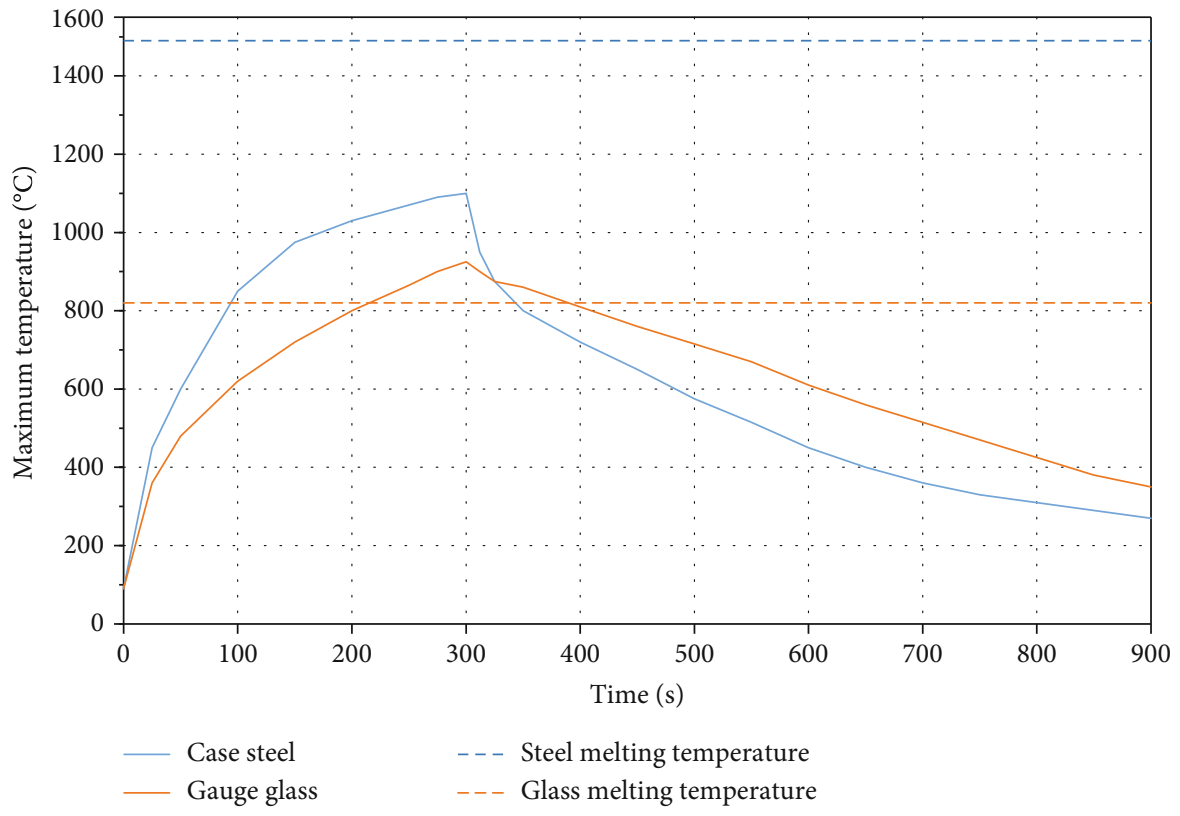

FIgURE 5: Dependence of maximum temperatures in material on time.

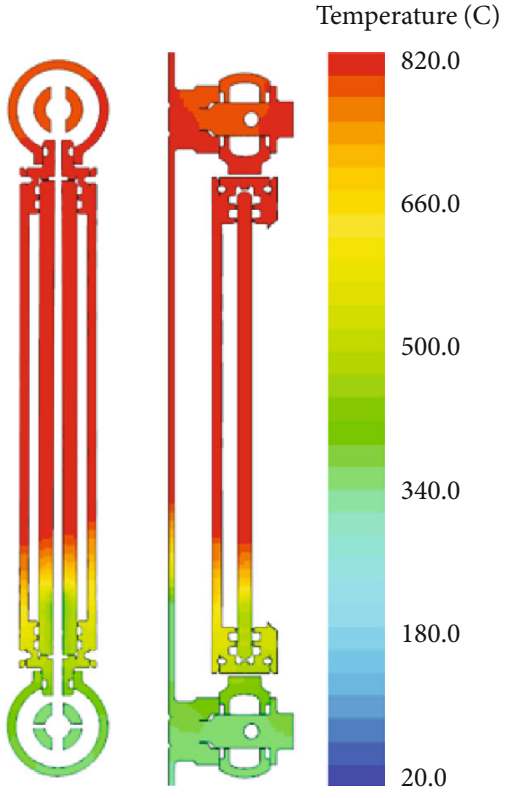

Figure 6: Temperature of the gauge glass at $t=5$ minutes.

resistance classification without additional material examination. However, two-fold excess of the temperature of the sealing elements over recommended working temperature indicates a high probability of the leakage through these sealing elements. When the flame is directed to the oil return pipe, the working temperature of the sealing elements in the calculations is already exceeded at $t_{2}^{\text {num }}=80 \mathrm{~s}$ and rises up to $T_{\text {sealing }}^{\max }=550^{\circ} \mathrm{C}$, which inevitably leads to degradation of the material and sealing depressurization, recorded in the experiment at $t_{2}^{\exp }=282 \mathrm{~s}$.

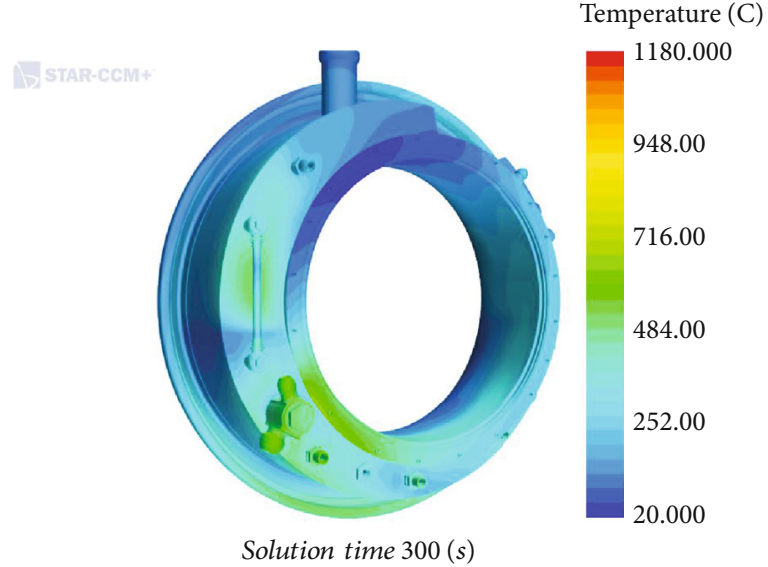

FIgURE 7: Temperature of the oil tank elements for oil return pipe fire zone at $t=5$ minutes.

Figure 9 shows temperature distribution of oil return pipe. Parts washed by oil have significantly lower temperature over the parts directly impacted by the flame.

3.3. Drain Valve Fire Zone. Figure 10 shows the temperature distribution on the oil tank surface at $t=5 \mathrm{~min}$. Similar to the oil return pipe case the temperature of the oil tank is much lower than in previous case since the flame is directed to the zone washed by oil. The only zone reaching $T_{\text {steel }}^{\max }=900^{\circ} \mathrm{C}$ is a thin flange at the outer radii of the oil tank. Figure 11 shows the value of maximum temperature of the components during the test. The temperature of the sealing element reaching upper operating limit of $T_{\text {sealing }}^{\text {operating }}=300^{\circ} \mathrm{C}$ at $t_{3}^{\text {num }}=256 \mathrm{~s}$, and the maximum temperature of the sealing observed during the fire resistance test is $T_{\text {sealing }}^{\max }=308^{\circ} \mathrm{C}$. Therefore, it can be concluded that 


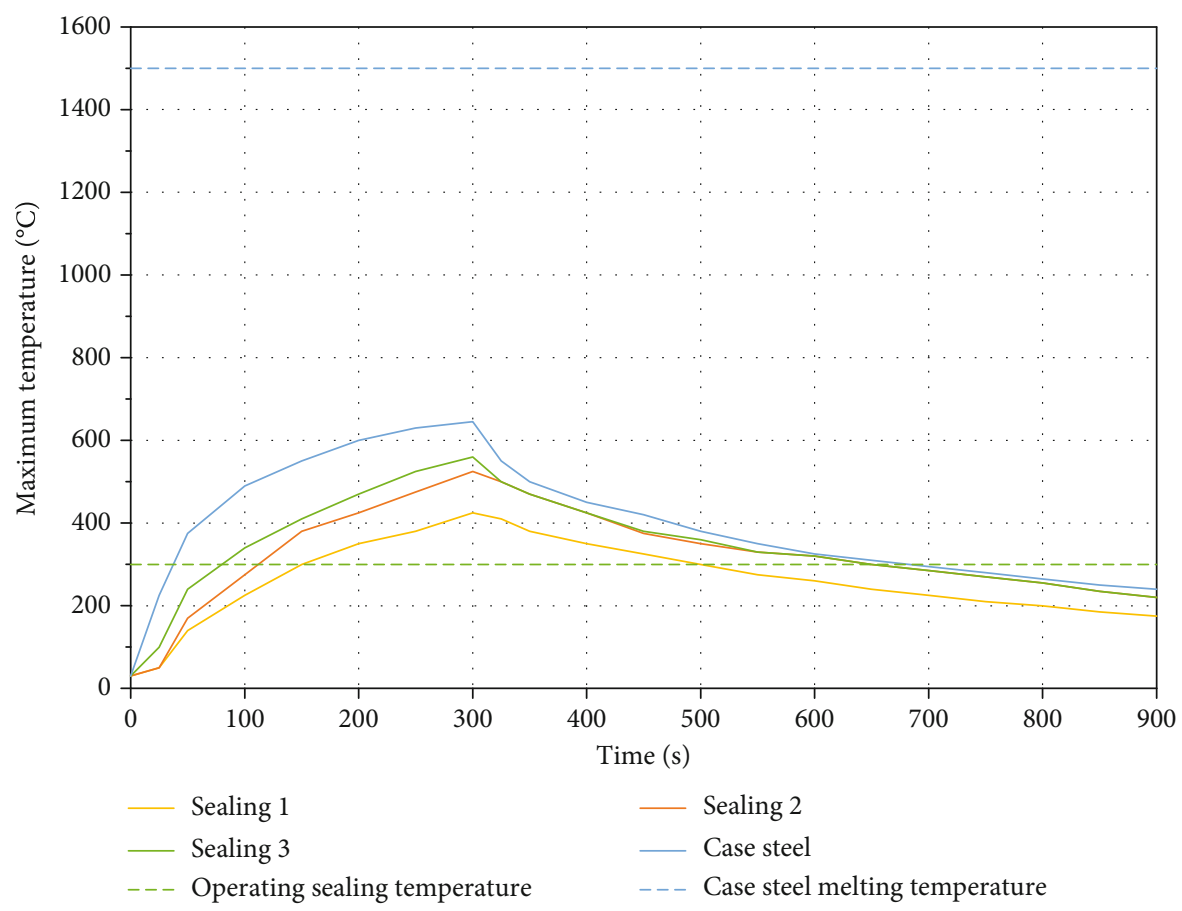

Figure 8: Dependence of maximum temperatures in material on time.

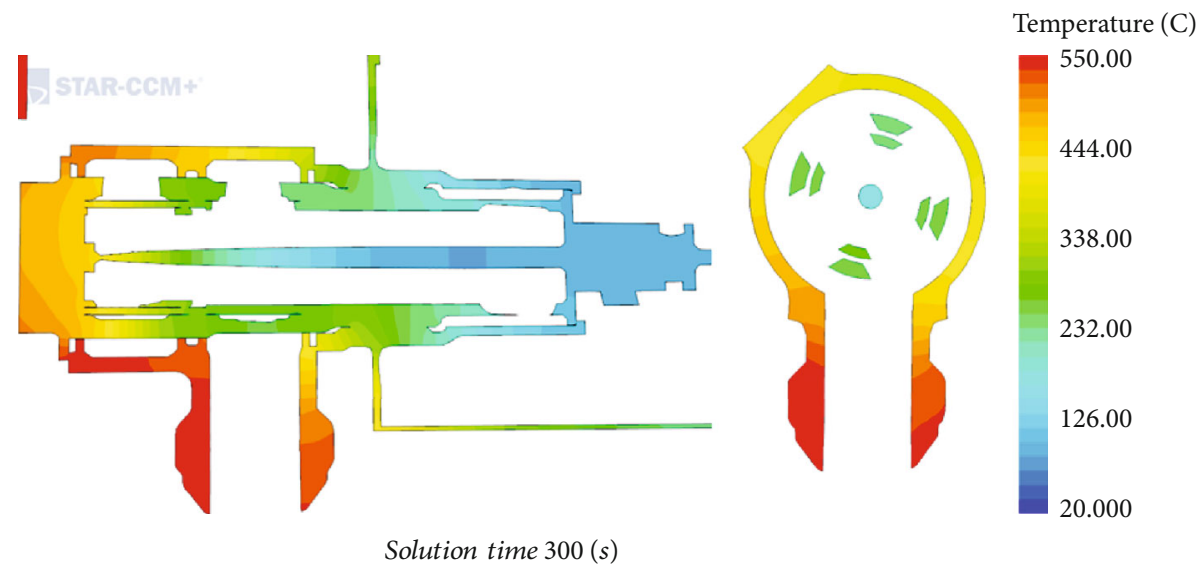

FIgURE 9: Temperature of the oil return pipe fire zone at $t=5$ minutes.

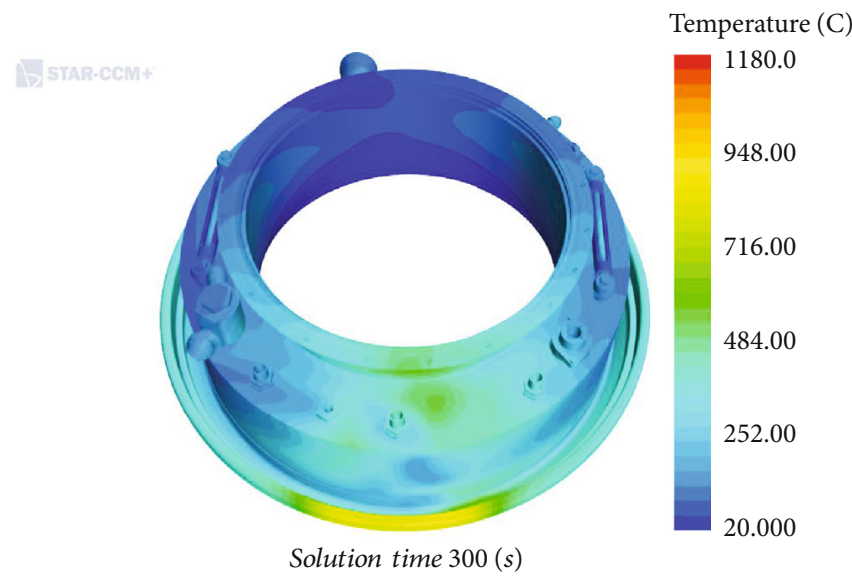

FIgURE 10: Temperature of the oil tank elements for drain valve fire zone at $t=5$ minutes. 


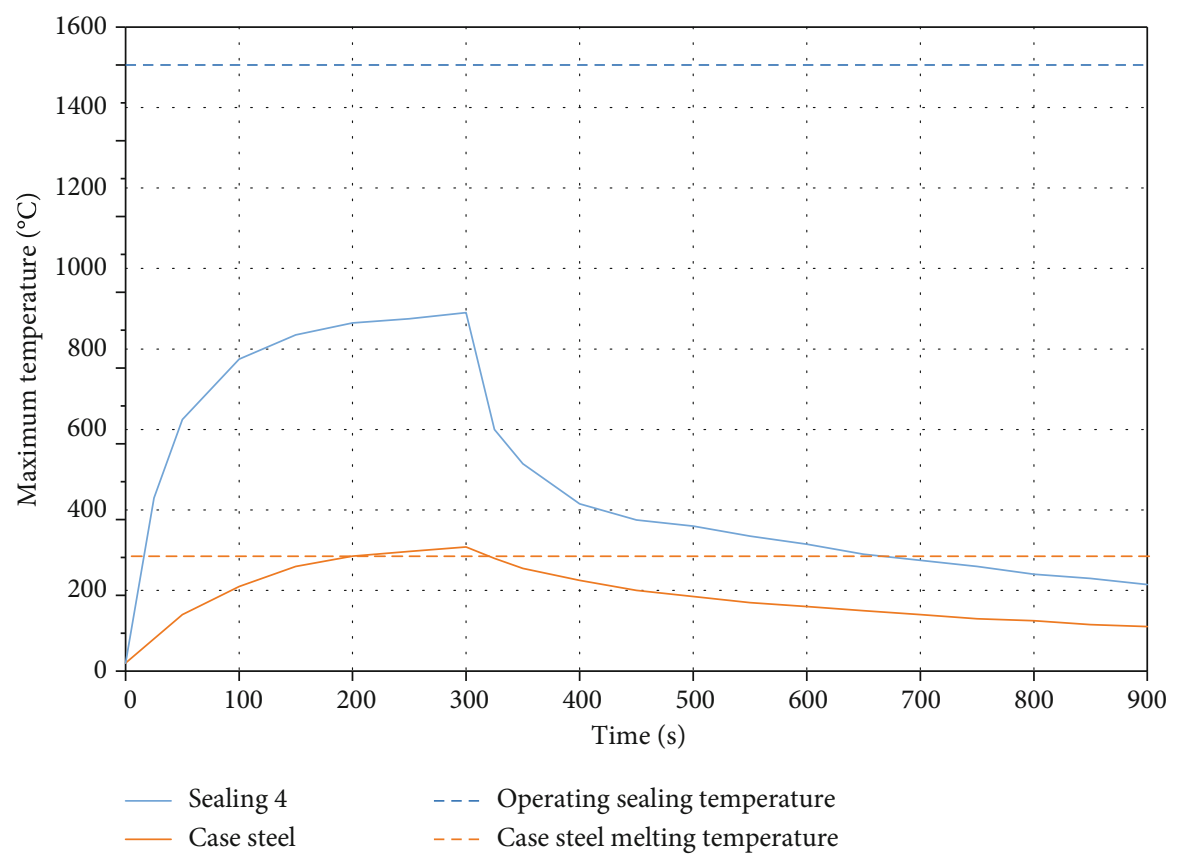

Figure 11: Dependence of maximum temperatures in material on time.
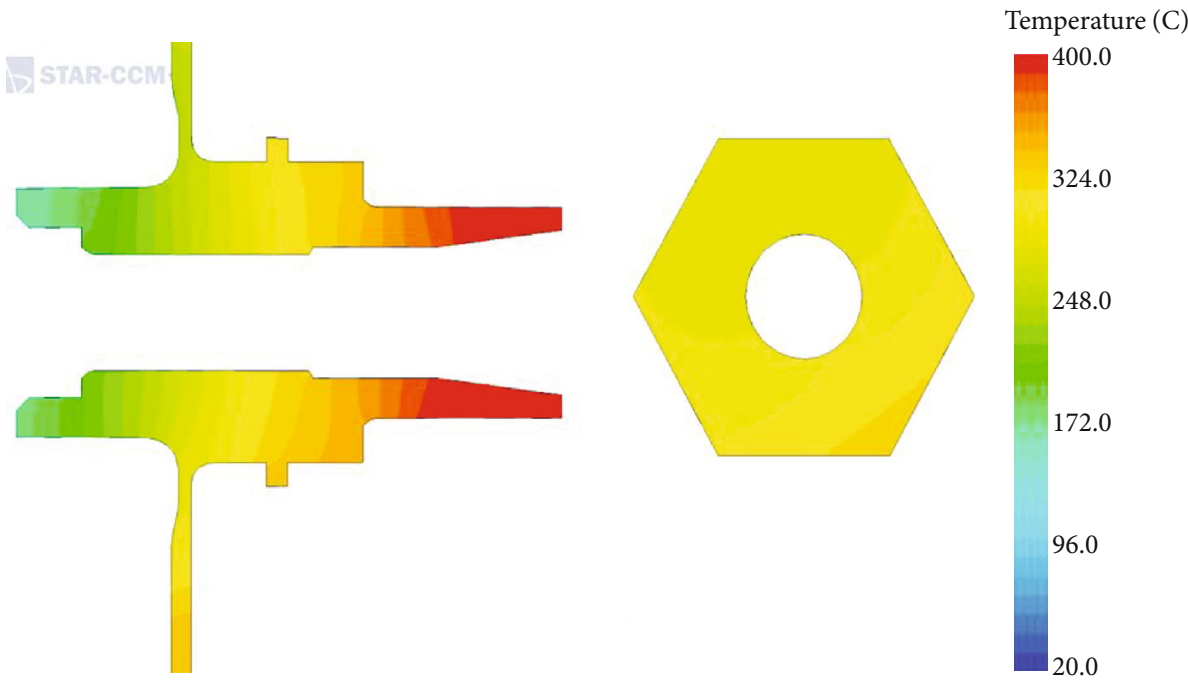

Solution time $300(s)$

Figure 12: Temperature of the drain valve at $t=5$ minutes.

for drain valve fire zone oil tank withstand the fire resistant classification, which perfectly fits experimental data, where no failure was observed. Figure 12 demonstrates temperature distribution on the drain valve. Since it is located at the bottom side of the oil tank, heat is removed by circulating oil and the temparature of the drain valve does not exceed $T_{\text {valve }}^{\max }=400^{\circ} \mathrm{C}$.

\subsection{Analysis and Comparison of Experimental and Numerical} Results. The presented independent results (numerical simulation has been performed as a "blind test" with latter comparison of the results) of the two approaches testify to their qualitative agreement. A direct quantitative comparison is impossible in this case, since the calculation problem was solved in order to conclude about the oil tank fire resistance, and attention was paid to meeting the fire resistance criterion rather than finding the exact depressurization time. Also, to determine the depressurization time of the sealing rings, there is a need in additional data for the ring material properties at high temperatures. This fact suggests that a detailed analysis, even with the numerical approach, requires experiments on samples of the material and leads to the use of the numerical-experimental approach in the development of new designs. Meanwhile, the results on the gauge glass melting in the numerical and experimental approaches are in a good agreement. 


\section{Conclusion}

Employment of the computational model has a number of significant advantages over the traditional experimental approach, including relatively low cost, the possibility to obtain a large amount of data on the product behavior, allowing an engineer to optimize the product at the design stage with minimum time requirements. However, to implement the calculation approach successfully, it is necessary to have material properties used in the component under high temperatures.

The performed research shows that at the current level of numerical simulation technology is mature enough to obtain accurate information on behavior of a complex components of the existing GTE under conditions of intense thermal effects, which is proved by good agreement between the numerical results and experimental data on representative temperatures and times.

\section{Data Availability}

The data used to support the findings of this study are available from the corresponding author upon request.

\section{Conflicts of Interest}

The authors declare that they have no conflicts of interest.

\section{Acknowledgments}

This study was sponsored by the Sarov Engineering Center (https://www.saec.ru). This study was also supported by the UEC-Klimov, which was greatly appreciated by the authors.

\section{References}

[1] Federal Aviation Regulations, CFR Part 33 Airworthiness Standards: Aircraft Engines, Federal Aviation Administration, Washington, 1993.

[2] The International Organization for Standardization, ISO2685, Aircraft Environmental Conditions and Test Procedures for Airbone Equipment - Resistance to Fire in Designated Fire Zones, Switzerland, 1998.

[3] R. Prieler, M. Mayrhofer, M. Eichhorn-Gruber, G. Schwabegger, and C. Hochenauer, "Development of a numerical approach based on coupled CFD/FEM analysis for virtual fire resistance tests-part A: thermal analysis of the gas phase combustion and different test specimens," Fire and Materials, vol. 43, no. 1, pp. 34-50, 2019.

[4] R. Prieler, H. Gerhardter, M. Landfahrer et al., "Development of a numerically efficient approach based on coupled CFD/FEM analysis for virtual fire resistance tests-part B: deformation process of a steel structure," Fire and Materials, vol. 44, no. 5, pp. 704-723, 2020.

[5] M. Malendowski and A. Glema, "Development and implementation of coupling method for CFD-FEM analyses of steel structures in natural fire," Procedia Engineering, vol. 172, pp. 692-700, 2017.

[6] S. L. Barbotko, O. A. Kirienko, O. S. Volny, and A. N. Lutsenko, "Analysis of fire hazard of aviation engine nacelles and other fire hazardous zones; methods of fire tests of mate- rials and structural elements for compliance with the requirements of aviation standards," Problems of flight safety, no. 5, pp. 3-24, 2017.

[7] N. Grange, K. Chetehouna, N. Gascoin, and S. Senave, "Numerical Study of the Thermal Behaviour of a ThermoStructural Aeronautical Composite under Fire Stress," in 2nd European Symposium of Fire Safety Science, Nicosia, Cyprus, 2015.

[8] Z. Wang, F. Jia, E. R. Galea, and J. Ewer, "Computational Fluid Dynamics Simulation of a Post-Crash Aircraft Fire Test," Journal of Aircraft, vol. 50, no. 1, pp. 164-175, 2013.

[9] J. C. G. Silva, A. Landesmann, and F. L. B. Ribeiro, "Performance-based analysis of cylindrical steel containment vessels exposed to fire," Fire Safety Journal, vol. 69, pp. 126-135, 2014.

[10] A. Paajanen, S. Hostikka, A. Matala, and R. Gutkin, "CFD-FEA simulation framework for composite structures in fire," ECCM16-16th European Conference on Composite Materials, 2014, pp. 22-26, Seville, Spain, June 2014.

[11] A. Neely and P. Ireland, "Pilot study to investigate novel experimental and theoretical fire-event modelling techniques," in 37th Aerospace Sciences Meeting and Exhibit, p. 326, Reno, NV, U.S.A., 1999.

[12] OST 1 14645-89, "Sealing Devices for radial movable and fixed joints with a rubber O-ring," Design.

[13] "Software STAR-CCM+, ver. 12.02," 2016, https://www.cdadapco.saec.ru/star-ccm.

[14] F. R. Menter, "Two-equation eddy-viscosity turbulence models for engineering applications," AIAA Journal, vol. 32, no. 8, pp. 1598-1605, 1994.

[15] S. Abaqus, "Ver. 6.14. Dassault Systems Simulia Corp., Providence, RI, USA,” 2014 r, https://www.caecis.com/abaqusunified-fea.

[16] L. M. Kachanov, Foundations of the Theory of Plasticity, L. M. Kachanov, Ed., Nauka, 1969.

[17] D. H. Norrie and G. J. De Vries, An Introduction to Finite Element Analysis, Academic Press, London, 1978.

[18] K. Y. Mokhov, A. V. Pogodin, A. Y. Kudryavtsev, and A. A. Ryabov, "Approaches for modeling burner heat impact during the fire resistance tests," in X International Conference on Thermofluids, Yogyakarta, Indonesia, 2019. 